\title{
DO WE NEED TO WEIGHT SATISFACTION SCORES WITH IMPORTANCE RATINGS IN MEASURING QUALITY OF LIFE?*
}

(Accepted 24 June 2005)

\begin{abstract}
Trauer and Mackinnon (2001; Quality of life research 10, pp. 579585) recently proposed that weighting satisfaction scores by importance ratings in measuring quality of life is undesirable and unnecessary. However, they didn't use empirical data to support their claim. In this study, different weighting algorithms developed by Cummins (1997; Comprehensive Quality of Life Scale - Adult: Manual [Deakin, University Australia]), Raphael et al. (1996; Journal of Adolescent Health 19, pp. 366-375), Ferrans and Powers (1985; Advances in Nursing Science 8, pp. 1524) and Frisch (1992; Comprehensive Casebook of Cognitive Therapy [Plenum Press, New York]) for measuring quality of life (QOL) were applied. Weighted scores computed from these weighting algorithms were compared with unweighted scores in predicting a global life satisfaction measure by correlation and moderated regression analyses. One hundred and thirty undergraduate students at National Taiwan University participated in the study voluntarily. They completed a 15 -item questionnaire on quality of campus life developed by the authors. They also completed the Satisfaction with Life Scale (SWLS), a global life satisfaction measure developed by Diener et al. (1985; Journal of Personality Assessment 49, pp. 71-75). The correlation results revealed that the weighted scores computed from different algorithms didn't have higher correlations to the SWLS than the unweighted scores. The moderated regression results also revealed that item importance did not moderate the relationship between item satisfaction and the overall life satisfaction. All these findings revealed that weighting satisfaction with importance is unnecessary.
\end{abstract}

KEY WORDS: importance, quality of life, satisfaction, weighting

\section{INTRODUCTION}

Weighting satisfaction scores with importance ratings at item level is a common scoring method in quality of life (QOL) measurement. Several instruments, such as the Comprehensive Quality Of Life Scale 
Adult-Fifth Edition (ComQol-A5; Cummins, 1997), the Quality of Life Profile-Adolescent version (Raphael et al., 1996), the Quality of Life Inventory (Frisch, 1992), the Quality of life index (Ferrans and Powers, 1985) and the Oral UK Oral Health Related Quality of Life measure (OHQoL-UK (W); McGrath and Bedi, 2004), to name a few, have adopted this scoring method. At first glance, it appears straightforward to use importance weighting, since different life aspects may have different importance for an individual's QOL. In other words, some life aspects may be more important to an individual's QOL and the corresponding items should contribute more to the total score of QOL (McGrath and Bedi, 2004).

However, Trauer and Mackinnon (2001) recently suggested that weighting satisfaction scores by importance ratings is undesirable and unnecessary. They presented three reasons: (1) the weighted scores are difficult to interpret; (2) the weighted scores have undesirable psychometric properties, such as non-ratio properties and correlations of the weighted scores with third variables varying systematically with the magnitudes of the means and SDs of importance ratings; (3) extreme dissatisfaction/satisfaction ratings were associated with higher importance ratings, suggesting that satisfaction ratings have incorporated the judgments of importance. Similar findings were also found in other areas, such as job satisfaction. In Locke's job satisfaction theory $(1969,1976)$, he had indicated that the importance of a job item is already included in and reflected by the item satisfaction ratings, and suggested that weighting satisfaction scores by importance ratings is redundant. Studies on job satisfaction had supported this argument (e.g., Mobley and Locke, 1970; Rice et al., 1991a, b; McFarlin and Rice, 1992; McFarlin et al., 1995) and also demonstrated that the satisfaction score with importance weighting was not superior to the unweighted score in predicting global job satisfaction measures (Mikes and Hulin, 1968; Waters, 1969; Waters and Roach, 1971; Ewen, 1967; Rice et al., 1991a; McFarlin and Rice, 1992; Staples and Higgins, 1998) or behavior criterions, such as employees' turnover (Mikes and Hulin, 1968; Waters and Roach, 1971).

Therefore, according to Trauer and Mackinnon (2001), Locke $(1969,1976)$ and related studies mentioned above, we may infer that the weighted satisfaction score on QOL measurements would not be superior to the unweighted score in the QOL research as well. Hsieh's 
(2003) result had supported this idea. In his study, he adopted three algorisms,

$$
\begin{aligned}
& \text { (1) } \mathrm{DI}=\sum\left(S_{i} \times I_{i}\right) / \sum I_{i}, \\
& \text { (2) } \mathrm{DI}_{\mathrm{sqrt}}=\sum\left(S_{i} \times \sqrt{I_{i}}\right) / \sum \sqrt{I_{i}} \text {, and } \\
& \text { (3) } \mathrm{DI}^{2}=\sum\left(S_{i} \times I_{i}^{2}\right) / \sum I_{i}^{2},
\end{aligned}
$$

(where $S_{i}$ is the satisfaction rating of item $i$ and $I_{i}$ is the value of the importance rating of item $i$ ), to compare weighted satisfaction scores with unweighted satisfaction scores in correlating global life satisfaction measures. The first algorithm assumed importance scale had linear effect on satisfaction weighting score, that is, it reserved the property of the equal distance between the values of ratings. The second algorithm assumed importance scale had non-linear effect on satisfaction weighting score, and the non-linear effect was increased at a decreasing rate by multiplying the square-root value of importance value. Finally, the third algorithm also assumed importance scale had non-linear effect on satisfaction weighting score, but the non-linear effect was increased at an increased rate by multiplying the square value of importance value. His results indicated that using importance rating as a weighting factor (either linear or nonlinear effect), did not improve the correlations with global life satisfaction measures.

However, the algorithms used in Hsieh's study were not commonly used in the existing QOL measurements. The commonly-used and well-established weighting algorisms proposed by Cummins (1997), Raphael et al. (1996), Frisch (1992), and Ferrans and Powers (1985) in the existing QOL measurements were not included in Hsieh's study (2003). These algorisms are adopted in the Comprehensive Quality of Life Scale-Adult-Fifth Edition, the Quality of Life Profile, the Quality of Life Inventory, and the Quality of Life Index, respectively. The differences between these algorisms and Hsieh's algorisms were (1) the algorisms proposed by Cummins (1997), Raphael et al. (1996), Frisch (1992), and Ferrans and Powers (1985) did not have the component on dividing the sum of importance weighing values as in Hsieh's algorisms and (2) these algorisms only concerned about the linear effect of importance value. They did not incorporate the non-linear effect of importance value as Hsieh's algorisms did. Therefore, it is obvious that the commonly-used and well-established 
weighting algorisms proposed by Cummins (1997), Raphael et al. (1996), Frisch (1992), and Ferrans and Powers (1985) have differences from Hsieh's algorisms. Since Hsieh (2003) did not include these algorisms in his study, the performance of these weighting algorisms has not been examined. And it is also unclear whether Hsieh's (2003) conclusion on satisfaction weighting by importance rating was still valid if the different and commonly-used weighting algorisms were applied. As a result, in this study, we attempted to use weighting algorisms developed by Cummins (1997), Raphael et al. (1996), Frisch (1992), and Ferrans and Powers (1985) to examine whether the weighted score is superior to the unweighted score in predicting a global life satisfaction measure.

Traditionally, the procedure that correlating weighted scores with a criterion variable (e.g., a global life satisfaction measure) was widely used to examine the effect of weighted scores, however, many researchers proposed that correlational approach was not an appropriate method to test the effect of multiplicative score (e.g., Glass, 1968; Schmidt, 1973; Arnold and Evans, 1979; Caston and Briato, 1983; Evans, 1991). The reason is that correlation between a product variable (such as the weighted score) and a third variable was dependent on the scales of the two original variables (Bohrnstedt and Goldberger, 1969; Schmidt, 1973; Arnold and Evans, 1979; Evans, 1991). On the exact covariance of products of random variables, Bohrnstedt and Goldberger (1969) showed that the correlation between a product variable and a third variable based on an assumption of multivariate normality is (as cited in Arnold and Evans, 1979)

$$
r_{z, x y}=\frac{\operatorname{cov}(z, x y)}{\sigma_{z} \sigma_{x y}}
$$

where

$$
\begin{aligned}
& \operatorname{cov}(z, x y)=\bar{x} \operatorname{cov}(y, z)+\bar{y} \operatorname{cov}(x, z) \\
& \sigma_{x y}^{2}=\bar{x}^{2} \sigma_{y}^{2}+\bar{y}^{2} \sigma_{x}^{2}+2 \overline{x y} \operatorname{cov}(x, y)+\sigma_{y}^{2} \sigma_{x}^{2}+\operatorname{cov}^{2}(x, y) \\
& \sigma_{z}^{2}=\frac{\sum(z-\bar{z})}{n}
\end{aligned}
$$


According to the preceding equations, the means and the variance of the two original variables ( $x$ and $y$ ) would influence the covariance and the variance of a product variable $(x y)$, and then, have substantial impact on the correlation involving the product variable. In other words, linear transformation of the two original variables alters their means, and then, results in fluctuation in the zero order correlation between the product variable $(x y)$ and a third variable $(z)$ (Arnold and Evans, 1979). In the context of importance weighting, this statistical property implies that the correlation coefficient between a weighted score and a global life satisfaction measure would be fluctuated by changing the zero-point on the interval scale of importance or satisfaction rating. As a result, correlation analysis could not provide a reliable result for examining the effect of importance weighting.

The appropriatiate method to examine the effect of product variable (such as the weighted score) is moderated regression analysis (Cohen, 1978; Arnold and Evans, 1979; Evans, 1991). Caston and Briato (1983), Rice et al. (1991a) and McFarlin and Rice (1992) have adopted this method to examine the effect of importance weighting. In their study, moderated regression analysis was used to regress a global job satisfaction score on item importance, item satisfaction and their interaction (the product of item importance and satisfaction) to see if the interaction term has significant effect in predicting the global job satisfaction. Thus, in order to examine the effect of importance weighting clearly, moderated regression analysis was further conducted to see if the item importance ratings moderate the relationships between item satisfaction and the overall life satisfaction. If the item importance had a moderating effect, that is, the interaction term created by multiplying item satisfaction with item importance was significant for predicting the overall life satisfaction, it could be concluded that the weighting item satisfaction by item importance is desirable in accounting for the overall life satisfaction. On the contrary, if the interaction term was not significant, we could suggest that the importance weighting has a minor role in accounting for individuals' overall life satisfaction.

Therefore, there were two parts in this study. First, we examined the performance of the weighting algorisms proposed by Cummins (1997), Raphael et al. (1996), Frisch (1992) and Ferrans and Powers 
(1985) to see whether the weighted score is superior to the unweighted score in predicting a global life satisfaction measure when correlation analysis was conducted. Although the correlation approach is not an ideal method to examine the effect of weighted score, many empirical studies still used this method to examine the effect of importance weighting and investigated the relations between weighted score and other variables, especially the studies that adopted by Cummins (1997), Raphael et al. (1996), Frisch (1992) and Ferrans and Powers' (1985) QOL instruments. To compare with these studies, the correlation analysis was still conducted.

Second, moderated regression analysis was conducted to examine the moderating effect of item importance on relationships between item satisfaction and the overall life satisfaction. The regression procedure can test the conceptual meaning of importance weighting directly. The idea that item satisfaction would have stronger relation with the overall life satisfaction among people who regards the item with higher importance than people who regards the item with lower importance could be examined empirically using moderated regression analysis. Based on these two parts, it is hoped to address the effect of importance weighting more clearly.

\section{METHOD}

\section{Subjects and Procedure}

One hundred and thirty undergraduate students $(55.4 \%$ female and $44.6 \%$ male) at National Taiwan University participated in the study voluntarily. The mean age was 19.98 years $($ std $=1.47)$. All questionnaires were filled out during approximately $30 \mathrm{~min}$ and then handed in to the researchers.

\section{Instruments}

Quality of campus life questionnaire

This questionnaire, developed by the authors, contains 15 items to measure college students' satisfaction with 15 different life domains on a Likert-typed scale ranging from 1 (very dissatisfied) to 5 (very satisfied). The contents of 15 items were living environment, campus environment, learning atmosphere, social and political environment, 
transport, money, eating, health, sleep, leisure activities, energy, non-study performance, learning performance, social relationships, and social support. These 15 life areas were selected in accordance with student life and they were selected by referencing different standard QOL measures, such as the WHOQOL-BREF Taiwan version (Yao et al., 2002), the Quality of Life Inventory (Frisch, 1992) and the Quality of Life index (Ferrans and Powers, 1985), etc. After completing satisfaction ratings, participants were asked to rate the importance of each item on a Likert-typed scale ranging from 1 (not at all important) to 5 (very important). In this study, the internal consistency (coefficient $\alpha$ ) of the satisfaction ratings and importance ratings were 0.82 and 0.86 , respectively.

\section{Satisfaction with life scale}

The Satisfaction with Life Scale (SWLS), developed by Diener et al. (1985), is a widely used measure of subjective well being. Adopting Shin and Johnson's (1978) perspective, Diener et al. (1985) defined life satisfaction as conscious cognitive judgment of life, in which individuals compare their life circumstances with a self-imposed standard. Because, different people may have very different ideas about what constitutes a good life, the SWLS was developed to assess satisfaction with the individual's life as a whole, creating a global evaluation of life satisfaction (Pavot and Diener, 1993). The scale contained 5 items and employed a 7-point Likert-type scale with higher values corresponding to a higher degree of satisfaction. In this study, the mean score was calculated to represent the level of satisfaction. The SWLS has shown good reliability and validity. The internal reliability was ranged from 0.79 to 0.89 . The test-retest reliability coefficients of the SWLS were 0.83 for 2 week interval, 0.84 for 1 month interval, 0.64 and 0.82 for 2 month interval in different studies (see Pavot and Diener, 1993). In addition, it has shown that the SWLS has only one factor and this single-factor solution has been replicated in different studies (Diener et al., 1985; Arrindell et al., 1991, 1999; Pavot et al., 1991; Shevlin, and Bunting, 1994; Lewis et al., 1995; Shevlin et al., 1998; Atienza et al., 2003; Westaway et al., 2003). Regarding validity, the SWLS demonstrated adequate construct validity, convergent validity and discriminant validity (see Pavot and Diener, 1993; Lucas et al., 1996; Arrindell et al., 1999). In Hong Kong published Chinese translated version, Sachs (2003) has 
shown that there was a single factor underlying the scale and demonstrated good validity of the scale. Besides, Wu and Yao's study (2005) also confirmed the single-factor structure of the SWLS-Taiwan version, and revealed the SWLS-Taiwan version was factor invariant across gender. In this study, the internal consistency (coefficient $\alpha$ ) of the scale was 0.89 .

\section{Weighting Algorisms}

\section{Cummins' algorism}

Cummins' algorism was adopted in the subjective QOL section of Comprehensive Quality of Life Scale-Adult-Fifth Edition (ComQolA5, Cummins, 1997). The subjective QOL section of ComQol-A5 comprises 7 items, including material well-being, health, productivity, intimacy, safety, place in community and emotional well-being. Respondents were asked to provide satisfaction and importance ratings for these 7 items. The seven-point Delighted-Terrible scale, ranging from 1 (terrible) to 7 (delighted), was used to measure satisfaction and the five-point Likert-type scale, ranging from 1 (not at all important) to 5, (could not be more important) was used to measure importance. When calculating weighted score, the satisfaction data was recoded as $-4,-3,-2,1,2,3$, and 4 (note that this recoding procedure is not a linear transformation). Then, the recoded satisfaction score was multiplied by importance score (scored $1-5)$. The possible range of weighted score was -20 to +20 . In the current study, since the satisfaction rating scale was five-point Likert-type scale, the original satisfaction value $(1,2,3,4$, and 5) was recorded as $-3,-2,1,2$, and 3 . Then, the recoded satisfaction score was multiplied by importance rating (scored 1-5). Therefore, the weighted score ranged from -15 to +15 .

\section{Raphael's algorism}

Raphael's weighting algorism was developed in the Quality of Life Profile (Raphael et al., 1996). The QOL Profile measures adolescent quality of life in three broad domains of adolescent functioning: being, belonging, and becoming. Being reflects "who one is", belonging concerns the personal fit with his/her environment, and becoming refers to activities carried out in the course of daily living (Raphael et al., 1996). Each domain has three subdomains, and each 
subdomain contains six items. Thus, the measure has 54 items. Participants were asked to provide satisfaction and importance ratings for these 54 items on the five-point Likert-type scale, ranging from 1 (no satisfaction at all/not at all important) to 5 (extremely satisfied/ extremely important $)$. Then, the formula: $[\mathrm{QOL}=($ Importance score $/ 3) \times($ satisfaction score -3$)$ ] was used to calculate weighted score for each item. The possible range of values was -3.33 to +3.33 . In this study, since the satisfaction rating scale and importance rating scale were five-point, the weighting formula was applied directly.

\section{Frisch's algorism}

Frisch's algorism was applied in the Quality of Life Inventory (Frisch, 1992), in which 16 domain satisfactions are assessed. The 16 domains are health, self-esteem, goals and values, money, work, play, learning, creativity, helping, love, friends, children, relatives, home, neighborhood, and community. There is one item for satisfaction rating and one item for importance rating for each domain. Thus, the Quality of Life Inventory has 32 items. In the Quality of Life Inventory, the six-point Likert-type scale anchoring $-3,-2,-1,1,2$, and 3 was used to measure satisfaction and the three-point Likerttype scale anchoring 0,1 , and 2 was used to measure importance. In computing weighted score, satisfaction score was multiplied by importance rating for each domain (at item level). The possible range of weighted score was -6 to +6 . In the current study, because the satisfaction rating scale was five-point, in order to be consistent with Frisch's formula and center the satisfaction scale on zero, the satisfaction score was recoded as $-2,-1,0,1$, and 2 . Besides, the original value of importance score with 1 was recorded as 0 , the original value with 2 or 3 was recorded as 1 , and the original value with 4 or 5 was recorded as 2 to be consistent with Frisch's importance scale. The weighted score was calculated by multiplying the recorded satisfaction score ( -2 to 2 ) and importance score ( 0 to 2$)$. The possible range of weighted score is -4 to +4 .

\section{Ferrans and Powers' algorism}

Ferrans and Powers' weighting algorism was developed in the Quality of Life Index (Ferrans and Powers, 1985), which contains five domain, including (1) overall QOL, (2) health and functioning, (3) psychological/spiritual, (4) social and economic, and (5) family. The 
Quality of Life Index measures both satisfaction and importance regarding various aspects of life. The six-point Likert-type scale ranging from 1 to 6 was used to measure satisfaction and importance. When calculating weighted score, the satisfaction scale was centered on zero by subtracting 3.5 from satisfaction response for each item. This produced responses of $-2.5,-1.5,-0.5,+0.5,+1.5$, and +2.5 . Then, the recoded satisfaction score was multiplied by importance rating (scored 1-6). The possible range of weighted score was -15 to +15 . After weighting satisfaction score with importance rating of each item, scores of items that belong to same domain were averaged and added 15 to provide five domain scores with positive value. In the current study, the five-point Likert-type satisfaction scale was centered on zero by subtracting 3 from satisfaction response for each item $(-2,-1,0,1$, and 2). Then, recoded satisfaction score was multiplied by importance rating (scored 1-5). The possible range of weighted score was -10 to +10 .

\section{RESULTS}

\section{Descriptive statistics of satisfaction and importance ratings}

The mean and standard deviation of raw satisfaction and importance scores for each item was presented in Table I. Generally, the campus environment, living environment, atmosphere of learning, and social support were the four most satisfied items and the social and political environment was the most dissatisfied item. On importance rating, health and sleep were the two items that had highest importance, and the social and political environment was the item that had lowest importance.

In addition, correlations of item satisfaction and item importance were generally not significant (ranging from -0.26 to 0.32 , with mean 0.03), consistent with the previous studies (e.g., McFarlin et al., 1995; Trauer and Mackinnon, 2001; Skevington et al., 2004). Although three items (i.e., money, non-study performance, and social support) had significant correlations, this result was also consistent with the previous findings that a few items would have significant correlations by chance (e.g., McFarlin et al., 1995; Trauer and Mackinnon, 2001; Skevington et al., 2004). Thus, this is a common finding in related studies. 


\section{Correlation Analysis Between Weighted/Unweighted Scores and the SWLS}

The correlations between unweighted and weighted satisfaction scores for the 15 items were presented in Table II. The result revealed that unweighted satisfaction scores and four weighted satisfaction scores were highly correlated for each item, almost above 0.90 . Further, the correlations of unweighted and weighted scores with the SWLS (satisfaction with life scale) score for each item were presented in Table III. According to the Table III, the correlation between unweighted score of an item and the SWLS was similar to the correlations between four weighted scores of the item and the SWLS.

Further, because the correlations in Table III were dependent correlations, in order to examine if the correlation between unweighted score of an item and the SWLS was significantly different from the correlations between four weighted scores of the item and the SWLS, the procedure for testing dependent correlations was applied (Cohen and Cohen, 1983). This method is limited to the three-variable case, that is, it can only test the difference among correlation between $X, Y$ and $Z$. In the current situation, the unweighted score, one of the weighted score and the SWLS were regarded as the three variables, so that the correlations of (unweighted score \& one of the weighted score), (unweighted score \& the SWLS) and (one of weighted score \& the SWLS) were included. The main focus was to compare if the correlations of (unweighted score $\&$ the SWLS) and (one of weighted score \& the SWLS) were significantly different. Take "living environment" item for example, what we want to know was if the correlation between unweighted score and the SWLS $(r=0.32)$ was statistically different from the correlation between the weighted score (computed by Cummins algorism) and the SWLS $(r=0.34)$. Therefore, the first step was to compute the correlations among the unweighted score, weighted score (computed by Cummins algorism) and the SWLS (the three correlations were 0.32, 0.34 and 0.92 ). And then, a $t$-test statistic on the dependent correlation comparison can be gained by the formula provided in Cohen and Cohen (1983, p. 57; a SPSS program was available at http:// www.utexas.edu/its/rc/answers/general/gen28.html). In this case, the $t$-test result was not significant $(t=0.60, \mathrm{df}=127, p>0.05)$, suggesting that the correlation between unweighted score and the SWLS 
TABLE I

Descriptive statistics of satisfaction and importance ratings on each item

\begin{tabular}{|c|c|c|c|c|c|}
\hline \multirow[t]{2}{*}{ Items } & \multicolumn{2}{|c|}{$\begin{array}{l}\text { Satisfaction } \\
\text { rating }\end{array}$} & \multicolumn{2}{|c|}{$\begin{array}{l}\text { Importance } \\
\text { rating }\end{array}$} & \multirow[t]{2}{*}{ Corr. } \\
\hline & Mean & Std. & Mean & Std. & \\
\hline 1. Living environment & 3.60 & 0.80 & 3.58 & 0.78 & 0.16 \\
\hline 2. Campus environment & 3.88 & 0.74 & 3.41 & 0.79 & 0.05 \\
\hline 3. Learning Atmosphere & 3.54 & 0.86 & 3.41 & 0.90 & 0.00 \\
\hline 4. Social and political environment & 2.32 & 0.75 & 2.97 & 1.03 & 0.01 \\
\hline 5. Transport & 2.92 & 0.97 & 3.33 & 0.93 & -0.06 \\
\hline 6. Money & 3.30 & 0.90 & 3.59 & 0.89 & $-0.26^{* *}$ \\
\hline 7. Eating & 3.40 & 0.82 & 3.45 & 0.90 & 0.10 \\
\hline 8. Health & 3.15 & 0.91 & 4.06 & 0.85 & 0.04 \\
\hline 9. Sleep & 2.70 & 0.95 & 4.05 & 0.89 & -0.12 \\
\hline 10. Leisure activities & 2.90 & 0.91 & 3.80 & 0.84 & -0.08 \\
\hline 11. Energy & 2.82 & 0.94 & 3.74 & 0.84 & -0.11 \\
\hline 12. Non-study performance & 3.03 & 1.03 & 3.33 & 0.83 & $0.32^{* *}$ \\
\hline 13. Learning performance & 2.78 & 0.89 & 3.62 & 0.86 & 0.04 \\
\hline 14. Interpersonal relationship & 3.32 & 0.97 & 3.88 & 0.89 & 0.14 \\
\hline 15. Social support & 3.52 & 0.91 & 3.92 & 0.85 & $0.23^{* *}$ \\
\hline
\end{tabular}

Note: (1) The column of Std. displayed the standard deviation of item satisfaction and item importance; (2) The column of Corr. displayed the correlations between item satisfaction and item importance.

${ }^{*} p<0.05,{ }^{* *} p<0.01$.

was not statistically different from the correlation between the weighted score (computed by Cummins algorism) and the SWLS.

The same procedure was applied to all correlations for each item. And all the results revealed that the correlations between unweighted scores and the SWLS were not different from the correlations between weighted scores and the SWLS. In addition, among different weighting algorithm, no one algorithm was consistently better than others. All these findings revealed that the correlations of weighted scores with the SWLS are not higher than those of unweighted scores with the SWLS.

\section{Moderated Regression Analysis on Importance Weighting}

In this section, moderated regression analysis was conducted to examine the moderating effect of importance weighting on the SWLS 


\section{TABLE II}

Correlations between unweighted and weighted satisfaction scores for the 15 items

\begin{tabular}{|c|c|c|c|c|}
\hline & Cummins & Raphael & Frisch & Ferrans \\
\hline Score range & $-15 \sim+15$ & $-3.33 \sim+3.33$ & $-4 \sim+4$ & $-10 \sim+10$ \\
\hline $\begin{array}{l}\text { 1. Living } \\
\text { environment }\end{array}$ & 0.92 & 0.97 & 0.94 & 0.97 \\
\hline $\begin{array}{l}\text { 2. Campus } \\
\text { environment }\end{array}$ & 0.91 & 0.96 & 0.92 & 0.96 \\
\hline $\begin{array}{l}\text { 3. Learning } \\
\text { Atmosphere }\end{array}$ & 0.91 & 0.96 & 0.93 & 0.96 \\
\hline $\begin{array}{l}\text { 4. Social and } \\
\text { political } \\
\text { environment }\end{array}$ & 0.87 & 0.88 & 0.83 & 0.88 \\
\hline 5. Transport & 0.92 & 0.95 & 0.93 & 0.95 \\
\hline 6. Money & 0.90 & 0.96 & 0.93 & 0.96 \\
\hline 7. Eating & 0.92 & 0.97 & 0.94 & 0.97 \\
\hline 8. Health & 0.95 & 0.98 & 0.97 & 0.98 \\
\hline 9. Sleep & 0.93 & 0.97 & 0.96 & 0.97 \\
\hline $\begin{array}{l}\text { 10. Leisure } \\
\text { activities }\end{array}$ & 0.94 & 0.98 & 0.97 & 0.98 \\
\hline 11. Energy & 0.94 & 0.98 & 0.96 & 0.98 \\
\hline $\begin{array}{l}\text { 12. Non-study } \\
\text { performance }\end{array}$ & 0.95 & 0.97 & 0.94 & 0.97 \\
\hline $\begin{array}{l}\text { 13. Learning } \\
\text { performance }\end{array}$ & 0.94 & 0.97 & 0.95 & 0.97 \\
\hline $\begin{array}{l}\text { 14. Interpersonal } \\
\text { relationship }\end{array}$ & 0.95 & 0.97 & 0.96 & 0.97 \\
\hline 15. Social support & 0.94 & 0.97 & 0.96 & 0.97 \\
\hline Total scores & 0.96 & 0.98 & 0.97 & 0.98 \\
\hline
\end{tabular}

Note: All correlation coefficients were significant at $p<0.001$.

for each item. In each regression model, the score of the SWLS was regressed on item satisfaction, item importance and the interaction term (item satisfaction $\times$ item importance). Raw scores (untransformed score) of item satisfaction and item importance were used in regression models. In order to avoid the collinearity resulting from the interaction term, raw scores of item satisfaction and item importance were centered in each model by subtracting the mean value from item satisfaction and item importance scores and the interaction term of item satisfaction and item importance was 


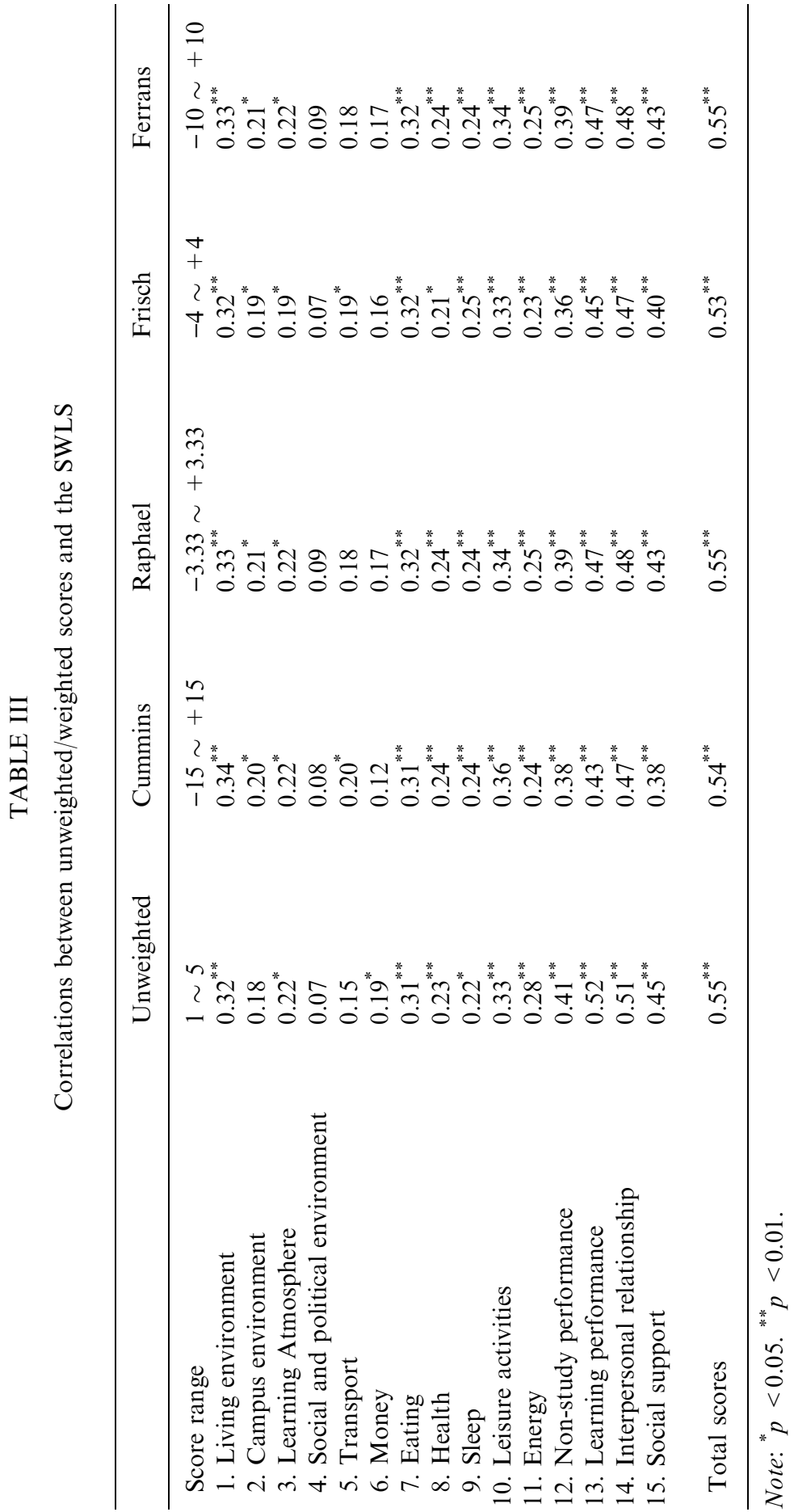


computed from the centered scores. If the interaction term had significant effect in predicting the SWLS, it could be concluded that item importance moderates the relationship between item satisfaction and the global life satisfaction.

The results of regression analyses were presented in Table IV. According to the results, item satisfaction generally had a significant effect on the SWLS, item importance generally had non-significant effect on the SWLS, and the non-significant interaction effect showed that item importance did not generally influence the degree to which item satisfaction contributes to the SWLS. Although several unexpected results were found, such as items on "campus environment", "social and political environment" and "transport" did not show significant effect of item satisfaction on the SWLS; item on "energy" had a significant effect of item importance on the SWLS (people with higher importance on Energy has higher global life satisfaction); and

TABLE IV

Coefficient of moderated regression models of the SWLS

\begin{tabular}{lllccl}
\hline Items & Constant & Item_sat & Item_imp & Interaction & $R^{2}$ \\
\hline 1. Living environment & 4.37 & $0.42^{* *}$ & 0.11 & 0.09 & 0.11 \\
2. Campus environment & 4.37 & 0.07 & -0.01 & $0.44^{*}$ & 0.08 \\
3. Learning Atmosphere & 4.38 & $0.27^{*}$ & 0.01 & 0.08 & 0.05 \\
4. Social and political & 4.37 & 0.11 & 0.06 & 0.21 & 0.02 \\
$\quad$ environment & & & & & \\
5. Transport & 4.39 & 0.17 & 0.08 & 0.15 & 0.04 \\
6. Money & 4.35 & $0.28^{*}$ & 0.08 & -0.11 & 0.05 \\
7. Eating & 4.37 & $0.40^{* *}$ & 0.08 & 0.10 & 0.10 \\
8. Health & 4.38 & $0.28^{* *}$ & 0.16 & 0.01 & 0.07 \\
9. Sleep & 4.39 & $0.27^{* *}$ & 0.03 & 0.15 & 0.07 \\
10. Leisure activities & 4.39 & $0.36^{* *}$ & 0.04 & 0.14 & 0.12 \\
11. Energy & 4.37 & $0.36^{* *}$ & $0.22^{*}$ & -0.10 & 0.11 \\
12. Non-study & 4.38 & $0.45^{* *}$ & -0.05 & -0.03 & 0.17 \\
$\quad$ performance & & & & & \\
13. Learning & 4.38 & $0.66^{* *}$ & 0.05 & -0.13 & 0.28 \\
$\quad$ performance & & & & & \\
14. Interpersonal & 4.38 & $0.61^{* *}$ & -0.16 & -0.02 & 0.27 \\
$\quad$ relationship & & & & & \\
15. Social support & 4.37 & $0.58^{* *}$ & -0.16 & 0.05 & 0.22 \\
\hline
\end{tabular}

Note: Item_sat $=$ item satisfaction; Item_imp $=$ item importance; Interaction $=$ Item_sat $\times$ Item_imp. ${ }^{*} p<0.05 .{ }^{* *} p<0.01$. 
item on "campus environment" had a significant interaction effect on the SWLS. These trivial results may occur by statistical chance and did not influence the general conclusion. In addition, regarding the interaction term, only one item (campus environment) had significant interaction effect on the SWLS. That is, only 1 out of 15 items had significant interaction effect. This positive result on the item of "campus environment" may occur by chance, since previous related studies (e.g., Rice et al., 1991a) also found trivial significant interaction term in their analyses.

In sum, it can be concluded that item importance did not moderate the relationship between item satisfaction and the global life satisfaction, suggesting that weighting item satisfaction with item importance did not contribute to predicting global life satisfaction.

\section{DISCUSSION}

In this study, weighting algorithms developed by Cummins (1997), Raphael et al. (1996), Frisch (1992) and Ferrans and Powers (1985) were applied to examine the effect of importance weighting by correlation analysis and moderated regression analysis. According to the correlation results, weighted scores computed by Cummins (1997), Raphael et al. (1996), Frisch (1992) and Ferrans and Powers' (1985) algorithms did not have better performance in correlating with the SWLS score than unweighted scores. However, as earlier mentioned, correlation analysis may not be an appropriate method to examine the effect of multiplicative score. The correlation coefficient between a product variable and a third variable would be changed if the scales of two original variables were linearly transformed. As a result, the correlation between a weighted score and a criterion variable was ambiguous to draw a solid conclusion. Therefore, moderated regression analysis was conducted to examine the moderating effect of item importance. Results of moderated regression analyses revealed that item importance did not moderate the relationship between item satisfaction and the overall life satisfaction. This finding showed that weighting satisfaction scores with importance rating did not have a beneficial effect in predicting the overall life satisfaction. Consequently, we can 
conclude that weighting satisfaction score with importance rating is unnecessary.

Although many studies have indicated weighting satisfaction scores with importance rating does not improve the explained variance of a global measure, Hsieh (2004) didn't think this is sufficient to justify the abandonment of incorporating importance weighting into QOL instruments. He thought that incorporating importance weighting into QOL instruments is appropriate, but the critical issue is how to weight. He has demonstrated that weighting satisfaction score with item importance ranks could improve the correlation between item satisfaction and global life satisfaction (2003). However, this result only occurred when the global life satisfaction is measured by single item. When the global life satisfaction measure is a multi-item scale, such as the LSIA (Life Satisfaction Index Assessment; Neugarten et al., 1961) and the SWLS, weighting item satisfaction scores with item importance ranks could not improve the correlation as well. Therefore, although Hsieh (2003) has demonstrated weighting satisfactions with item importance ranks could have better performance in correlating with a single-item global life satisfaction measure, it was not cogent enough to conclude that weighting satisfaction score with importance ranking or rating is appropriate, especially in the situation where the global life satisfaction measure is a multi-item scale. In addition, the finding of Hsieh (2003) was based on correlation analysis rather than moderated regression analysis, a better method to examine the weighting effect. Therefore, the finding of Hsieh (2003) should be further investigated and replicated.

Moreover, according to Locke's theory $(1969,1976)$, the importance of job item is already included in and reflected by the item satisfaction ratings. In his theory, he proposed that responses of satisfaction reflect a dual value judgment: (1) the discrepancy between what the individual wants and what he/she perceives himself/herself as getting, and (2) the importance of what is wanted to the individual, and also proposed that the level of satisfaction was influenced by the interaction of have-want discrepancy and importance (Locke, 1976). That is, given the amount of discrepancy, items with higher personal importance can produce a wider affective reaction ranging from greater satisfaction to greater dissatisfaction, and items with lower personal importance, on the other hand, only produce a more 
restricted affective reaction to the neutral point of the satisfactiondissatisfaction dimension.

This range-of-affect hypothesis was supported by empirical studies on job satisfaction (Mobley and Locke, 1970; Rice et al., 1991a, b; McFarlin and Rice, 1992; McFarlin et al., 1995) showing that satisfaction ratings already reflect a personal appraisal of the importance of the item. Thus, according to Locke's theory (1976), if the satisfaction ratings already reflect the importance of the item, weighting satisfaction scores with either importance rating or ranking is redundant. Rice et al.'s (1991a) study has supported this idea. In their study, they used seven alternative measures for assessing the item importance, including four rating methods, two ranking methods, and a point-distribution method. Although a composite importance value of each item was computed from these seven measures and used to examine Locke's hypothesis in further analysis, in their discussion section, they also indicated that "three of the individual measures of facet (item) importance came quite close to matching the results provided by the composite measure of importance: Rating 1 (the direct rating of importance on a 9-point scale), Rank 2 (the ranking of facets in terms of how important it is to get as much as is wanted), and Points (the distribution of 100 points to reflect the relative importance of each job facet)(p.38)". Their result suggested that item importance value gained from ranking method also fits Locke's model on item satisfaction and implied that weighting satisfaction score with importance ranking is unnecessary as well.

Therefore, according to the Locke's framework, there are three rules that can be summarized as (1) perceived have-want discrepancy of an item is a significant predictor for item satisfaction, (2) item importance moderates the relationship between perceived have-want discrepancy and item satisfaction, but (3) item importance does not moderate the relationship between item satisfaction and global satisfaction. These three rules have been supported in the previous studies (e.g., Rice et al., 1991a; McFarlin and Rice, 1992; McFarlin et al., 1995), however, in this study, the first two rules cannot be examined, because we did not measure the items' have-want discrepancy in this study. But the third rule was supported from the Table IV. It is obvious that item importance did not moderate the relationship between item satisfaction and the SWLS (global satisfaction). Generally, the non-significant moderation effect of item 
importance on the relationship between item satisfaction and global satisfaction can be explained by Locke's $(1969,1976)$ range-of-affect hypothesis. However, this explanation was speculated from Locke's theory. Further and full examination of Locke's theory is need. Specifically, item have-want discrepancy should be incorporated to provide cogent evidence on this issue.

In addition, the current sample is relatively homogenous (i.e., university students at NTU in Taiwan). In the future study, more heterogeneous populations should be used to cross-validate the current results. However, we did not think the results would be different from the current study. According to Locke's $(1969,1976)$ theory, if the importance rating has its psychological meaning and mechanism on satisfaction evaluation, then, it can be expected that samples from heterogeneous population or other developed or developing countries may also show the same finding that weighting importance rating on satisfaction scores is unnecessary. For example, subjects in Rice et al.'s (1991) study consisted of 97 employed college students worked in many different organizations from Buffalo, New York. In addition, 675 employees of a large midwestern bank in USA participated in McFarlin and Rice's (1992) study. The employees were characterized by diversity in education and position. In sum, this two nominated studies have subjects with diversity in background and were conducted in developing countries. However, Locke's hypothesis was supported in these two studies. Thus, this may illustrate that studies with heterogeneous population in developing countries also exhibit the same result derived from Locke's hypothesis. Although these two studies were conducted in the context of job satisfaction, it would be expected that the same result may be gained in the context of life satisfaction. Generally, according to Trauer and Mackinnon $(2001)$, Locke $(1969,1976)$ and the results of this study, it could be said that weighting satisfaction score with importance score is unnecessary.

\section{ACKNOWLEDGEMENT}

This study was supported by National Science Council (NSC 922320-B-002-172) and partially supported by the National Health Research Institute (NHRI-EX93-9204PP). 


\section{NOTE}

*This paper was a part of the first author's Master Thesis.

\section{REFERENCES}

Arnold, H.J. and M.G. Evans: 1979, 'Testing multiplicative models does not require ratio scales', Organizational Behavior and Human Performance 24, pp. 41-59.

Arrindell, W.A., J. Heesink and J.A. Feij: 1999, 'The Satisfaction with Life Scale (SWLS): Appraisal with 1700 health young adults in the Netherlands', Personality and Individual Differences 26, pp. 815-826.

Arrindell, W.A., L. Meeuwesen and F.J. Huyse: 1991, 'The Satisfaction with Life Scale (SWLS): Psychometric properties in a non-psychiatric medical outpatients sample', Personality and Individual Differences 12, pp. 117-123.

Atienza, F.L., I. Balaguer and M.L. Garcia-Merita: 2003, 'Satisfaction with Life Scale analysis of factorial invariance across sexes', Personality and Individual Differences 35, pp. 1255-1260.

Bohrnstedt, G. and A. Goldberger: 1969, 'On the exact covariance of products of random variables', Journal of the American Statistical Association 64, pp. 14391442.

Caston, R.J. and R. Briato: 1983, 'On the use of facet importance as a weighting component of job satisfaction', Educational and Psychological Measurement 43, pp. 339-350.

Cohen, J.: 1978, 'Partialed products are interactions: Partialed powers are curve components', Psychological Bulletin 85, pp. 858-866.

Cohen, J. and P. Cohen: 1983, Applied Multiple Regression/Correlation Analysis for the Behavioral Sciences (Lawrence Erlbaum Associates, Hillsdale, NJ).

Cummins, R.A.: 1997, Comprehensive Quality of Life Scale - Adult: Manual (University Australia, Deakin).

Diener, E., R.A. Emmons, R.J. Larsen and S. Griffin: 1985, 'The Satisfaction with Life Scale', Journal of Personality Assessment 49, pp. 71-75.

Evans, M.G.: 1991, 'The problem of analyzing multiplicative composites: Interactions revisited', American Psychologist 46, pp. 6-15.

Ewen, R.B.: 1967, 'Weighting components of job satisfaction', Journal of Applied Psychology 51, pp. 68-73.

Ferrans, C. and M. Powers: 1985, 'Quality of life index: development and psychometric properties', Advances in Nursing Science 8, pp. 15-24.

Frisch, M.B.: 1992, Use of the Quality of Life Inventory in problem assessment and treatment planning for cognitive therapy of depression, in A. Freeman and F.M. Dattlio (eds.), Comprehensive Casebook of Cognitive Therapy (Plenum Press, New York).

Glass, G.V.: 1968, 'Correlations with products of variables: derivations and implications for methodology', American Educational Research Journal 5, pp. 721-728.

Hsieh, C.M.: 2003, 'Counting importance: The case of life satisfaction and relative domain importance', Social Indicators Research 61, pp. 227-240.

Hsieh, C.M.: 2004, 'To weight or not to weight: the role of domain importance in quality of life measurement', Social Indicators Research 68, pp. 163-174. 
Lewis, C.A., M.E. Shevlin, B.P. Bunting and S. Joseph: 1995, 'Confirmatory factor analysis of the satisfaction with life scale: replication and methodological refinement', Perceptual and Motor Skills 80, pp. 304-306.

Locke, E.A.: 1969, 'What is job satisfaction?', Organizational Behavior and Human Performance 4, pp. 309-336.

Locke, E.A.: 1976, The nature and causes of job satisfaction, in M.D. Dunnette (ed.), Handbook of Industrial and Organizational Psychology (Rand McNally, Chicago), pp. 1297-1343.

Lucas, R.E., E. Diener and E. Suh: 1996, 'Discriminant validity of well-being measures', Journal of Personality and Social Psychology 71, pp. 616-628.

McGrath, C. and R. Bedi: 2004, 'Why are we "weighting"? An assessment of a selfweighting approach to measuring oral health-related quality of life', Community Dentistry and Oral Epidemiology 32, pp. 19-24.

McFarlin, D.B., E.A. Coster, R.W. Rice and T. Coopper-Alison: 1995, 'Facet importance and job satisfaction: Another look at the range of affect hypothesis', Basic and Applied Social Psychology 16, pp. 489-502.

McFarlin, D.B. and R.W. Rice: 1992, 'The role of facet importance as a moderator in job satisfaction processes', Journal of Organizational Behavior 13, pp. 41-54.

Mikes, P.S. and C.L. Hulin: 1968, 'Use of importance as weighting component of job satisfaction', Journal of Applied Psychology 52, pp. 394-398.

Mobley, W.H. and E.A. Locke: 1970, 'The relationship of value importance to satisfaction', Organisational Behavior and Human Performance 5, pp. 463-483.

Neugarten, B.L., R.J. Havighurst and S.S. Tobin: 1961, 'The measurement of life satisfaction', Journal of Gerontology 16, pp. 134-143.

Pavot, W. and E. Diener: 1993, 'Review of the satisfaction with life scale', Psychological Assessment 5, pp. 164-172.

Pavot, W., E. Diener, C.R. Colvin and E. Sandvik: 1991, 'Further validation of the Satisfaction evidence for the cross-method convergence of well-being', Social Indicators Research 28, pp. 1-20.

Raphael, D., E. Rukholm, I. Brown, P. Hill-Bailey and E. Donato: 1996, 'The quality of life profile-Adolescent version: Background, description, and initial validation', Journal of Adolescent Health 19, pp. 366-375.

Rice, R.W., D.A. Gentile and D.B. McFarlin: 1991a, 'Facet importance and job satisfaction', Journal of Applied Psychology 76, pp. 31-39.

Rice, R.W., K. Markus, R.P. Moyer and D.B. McFarlin: 1991b, 'Facet importance and job satisfaction: Two experimental tests of Locke's range of affect hypothesis', Journal of Applied Social Psychology 21, pp. 1977-1987.

Sachs, J.: 2003, 'Validation of the Satisfaction with Life Scale in a sample of Hong Kong University students', Psychologia 46, pp. 225-234.

Schmidt, F.L.: 1973, 'Implications of a measurement problem for expectancy theory research', Organizational Behavior and Human Performance 10, pp. 369-368.

Shevlin, M.E., V. Brunsden and J.N.V. Miles: 1998, 'Satisfaction with Life Scale: analysis of factorial invariance, mean structures and reliability', Personality and Individual Differences 25, pp. 911-916.

Shevlin, M.E. and B.P. Bunting: 1994, 'Confirmatory factor analysis of the satisfaction with life scale', Perceptual and Motor Skills 79, pp. 1316-1318.

Shin, D.C. and D.M. Johnson: 1978, 'Avowed happiness as an overall assessment of the quality of life', Social Indicators Research 5, pp. 475-492. 
Skevington, S.M., K. O'connell and the WHOQOL Group: 2004, 'Can we identify the poorest quality of life? Assessing the importance of quality of life using the WHOQOL-100', Quality of Life Research 13, pp. 23-34.

Staples, D.S. and C.A. Higgins: 1998, 'A study of the impact of factor importance weightings on job satisfaction measures', Journal of Business and Psychology 13, pp. 211-232.

Trauer, T. and A. Mackinnon: 2001, 'Why are we weighting? The role of importance ratings in quality of life measurement', Quality of life research 10, pp. 579-585.

Waters, L.K.: 1969, 'The utility of importance weights in predicting overall job satisfaction and dissatisfaction', Educational and Psychological Measurement 29, pp. 519-522.

Waters, L.K. and D. Roach: 1971, 'Comparison of unweighted and importanceweighted job satisfaction measures for three samples of female office workers', Psychological Reports 28, pp. 779-782.

Westaway, M.S., C. Maritz and N.J. Golele: 2003, 'Empirical testing of the satisfaction with life scale: A South African pilot study', Psychological Reports 92, pp. $551-554$.

Wu, C.H. and G. Yao.: 2005, 'Analysis of factorial invariance across genders in the Chinese version of the satisfaction with life scale', Manuscript submitted for publication.

Yao, G., C.W. Chung, C.F. Yu and J.D. Wang: 2002, 'Development and verification of reliability and validity of the WHOHR-QOL-BREF Taiwan version', Journal of the Formosan Medical Association 101, pp. 342-351.

Department of Psychology

Grace Yao

National Taiwan University

1, Sec. 4, Roosevelt RD.,

Taipei, Taiwan

E-mail: kaiping@ntu.edu.tw 